\title{
Teorias da democracia e a práxis política e social brasileira: limites e possibilidades
}

LORENA MADRUGA MONTEIRO

JOANA TEREZA UAZ DE MOURA

ALAN DANIEL FREIRE LACERDA"

\section{Resumo}

Este trabalho percorre as teorias da democracia - desde aquelas que enfatizam o seu caráter competitivo, realista, formal, passando por aquelas que destacam seu aspecto deliberativo, plebiscitário e participativo, até as que consideram primordial enfatizar seu caráter igualitário e substantivo - buscando demonstrar o alcance, as convergências e os limites de tais teorias. Mais do que apenas enfatizar as diferenças, contradições e o caráter normativo entre tais arcabouços teóricos, busca-se evidenciar em que aspectos as instituições e as experiências democráticas contemporâneas respondem de forma significativa e convergente as questões colocadas por essas teorias no Brasil.

Palavras-chave: Teorias da democracia. Participação. Representação. Democracia brasileira.

\footnotetext{
Instituto de Tecnologia e Pesquisa e Centro Universitário Tiradentes (Brasil)

"* Universidade Federal do Rio Grande do Norte (Brasil)

${ }^{* * *}$ Universidade Federal do Rio Grande do Norte (Brasil)
} 


\title{
Theories of democracy and the Brazilian political and social praxis: limits and possibilities
}

\begin{abstract}
This work explores the theories of democracy - from those that emphasize its competitive, realist and formal nature, including the ones that highlight its deliberative, plebiscitary and participative aspects, to those that emphasize its substantive and egalitarian character - seeking to demonstrate the scope, the convergences and the limits of such theories. More than just emphasizing the differences, contradictions and the normative character of such theoretical frameworks, we seek to reveal the aspects in which the institutions and democratic contemporary experiences respond significantly to the questions raised by these theories in Brazil.
\end{abstract}

Keywords: Theories of democracy. Representation. Participation. Brazilian democracy.

\section{Introdução}

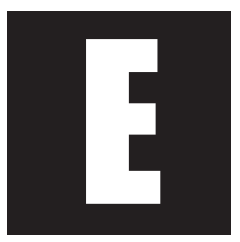

ste trabalho percorre as teorias da democracia - desde aquelas que enfatizam o seu caráter competitivo, realista, formal, passando por aquelas que destacam seu aspecto deliberativo, plebiscitário e participativo, até as que consideram primordial enfatizar seu caráter igualitário - buscando demonstrar o alcance, as convergências e os limites de tais teorias em relação às experiências democráticas contemporâneas, como a brasileira.

A despeito das divergências e conflitos existentes entre as teorias da democracia, objetiva-se destacar, neste artigo, os aspectos aos quais as instituições e as experiências democráticas contemporâneas respondem de forma significativa e convergente as questões colocadas por essas teorias. Ou seja, ainda que de modo preliminar e abrangente, o que impossibilita inferências mais conclusivas, este trabalho busca delimitar que, 
Sociologias, Porto Alegre, ano 17, oo 38, jan/abr 2015, p. 156-191

no mundo prático, tais pressupostos teóricos encontram acolhida, independentemente do modelo de democracia adotado, o que produz certos resultados políticos e sociais, embora ainda, de modo geral, insuficientes quando se associa democracia a justiça social.

Para tanto, o trabalho está dividido em três partes. Inicialmente apresentam-se os principais argumentos, limites e possibilidades das teorias da democracia. Depois, analisam-se as experiências concretas as quais incorporam uma série de pressupostos associados a esses modelos teóricos tratando, a partir da literatura especializada, das possibilidades e dos limites que encontram no mundo prático, no caso, na democracia brasileira. Por fim, apresenta-se uma discussão preliminar, objetivando auxiliar futuras avaliações empíricas do rendimento democrático das diversas inovações institucionais implantadas no Brasil.

\section{Teorias da democracia: pressupostos, limites e possibilidades}

A teoria da democracia competitiva ou procedimental e minimalista - tal como caracterizada por Joseph Schumpeter - teve sua origem associada às colocações de Max Weber acerca da institucionalização do Estado racional-burocrático no contexto do desenvolvimento do sistema capitalista de produção. Sinteticamente, Weber via a instauração de instituições políticas, em especial o Parlamento, como meios de limitar a ação da burocracia estatal. Desse modo, a preocupação manifesta por Weber refere-se às formas de conter e controlar a força das camadas burocráticas, tarefa à qual o Parlamento tem posição institucional privilegiada

Só um Parlamento ativo e não um parlamento onde apenas se pronunciam arengas pode proporcionar o terreno para o crescimento e ascensão seletiva de líderes genuínos, e não meros talentos demagógicos. Um Parlamento ativo, entretanto, é 
Sociologias, Porto Alegre, ano 17, no 38, jan/abr 2015, p. 156-191

um Parlamento que supervisiona a administração participando continuamente do trabalho desta. (Weber, 1980, p. 38)

Portanto, a Democracia Parlamentar, para Weber, tem como função primordial a seleção de líderes políticos. Nesse sentido, o Parlamento seria composto, não pelos burocratas e técnicos do Estado, mas sim por políticos profissionais selecionados pela sociedade por sua competência e capacidade. Essa é a forma de seleção que Weber classifica de democrática, ou seja, um processo de escolha dos líderes dirigentes gerado pela competição eleitoral. Portanto, a democracia caracterizava-se, de forma restrita, como um sistema que organizava a disputa entre as elites políticas, em que o Parlamento deveria transitar da política negativa (de representação de interesses e fiscalização do poder executivo) para uma política positiva, ou propositiva, desde que esse órgão tivesse uma participação efetiva na condução do governo (Sell, 2010, p. 140).

A eleição do corpo político, desse modo, é a questão fundamental nas democracias parlamentares. Como a burocratização das esferas do Estado se desenvolve da mesma maneira que na economia, os políticos, eleitos por suas competências e capacidades, devem ser a força de equilíbrio contra a dominação burocrática. A burocracia, por sua vez, deve se sujeitar ao controle político, dado que apenas a cooperação entre burocratas e políticos garantirá a supervisão contínua da administração, e com ela a educação política de líderes e liderados (Weber, 1980, p. 41-42).

Portanto, a Democracia é um modo de seleção e formação do corpo político na qual a participação política não é o elemento fundamental. A participação do povo limita-se à colaboração e votação durante as eleições, que ocorrem em intervalos relativamente longos, a discussão de resoluções, cujos efeitos são sempre controlados em grande escala pelos líderes (Weber, 1980, p. 68). 
Sociologias, Porto Alegre, ano 17, no 38, jan/abr 2015, p. 156-191

Nessa direção, Joseph Schumpeter, na década de 1940, com a obra "Capitalismo, Socialismo e Democracia", caracterizou a democracia como um método, um procedimento de escolha dos dirigentes políticos. Deste modo, a democracia é nomeada como procedimental, porque se define apenas como um sistema de regras para a escolha daqueles líderes os quais tomariam as decisões políticas que garantiriam ou não o bem comum da comunidade que os escolheu, uma vez que o método democrático é um sistema institucional para a tomada de decisões políticas, no qual o individuo adquire o poder de decidir mediante uma luta competitiva pelos votos do eleitor (Schumpeter, 1961, p. 328). Logo, a democracia caracteriza-se como um procedimento minimalista, com pouco ou nenhum valor substantivo, como um arranjo para formalizar as decisões coletivas pelo voto popular.

Como Schumpeter (1961) associava o processo político ao mercado econômico, acabou por apresentar uma perspectiva negativa acerca da busca do bem comum entre os cidadãos. Ou seja, como pressupõe que os indivíduos escolhem os líderes políticos a partir de fatores externos às suas necessidades sociais e políticas, assim como acontece na esfera econômica, vê a sociedade como um composto de indivíduos sem a possibilidade de construção de vontades coletivas (Miguel, 2002, p. 500).

Assim sendo, os cidadãos ou a comunidade, dentro desse método democrático, têm um envolvimento político mínimo, representado pelo ato de votar nos pleitos eleitorais, participar de instituições políticas, tais como os Partidos Políticos (que organizam e disputam votos nesse mercado competitivo) e utilizar-se de uma avaliação retrospectiva dos candidatos, caso rejeite a prática política anterior deles. Portanto, o que determina a democracia é a forma de seleção dos dirigentes políticos, como argumenta Schumpeter (1961, p.329): Essa ação justifica-se pelo fato de que a democracia parece implicar um método reconhecido, através do 
Sociologias, Porto Alegre, ano 17, no 38, jan/abr 2015, p. 156-191

qual se desenrola a luta competitiva, e que o método eleitoral é praticamente o único exeqüível, qualquer que seja o tamanho da comunidade.

Portanto, enquanto Weber rejeitava a participação do povo na condução da vida política pela sua natureza afetiva, passional, destacando a importância do Parlamento como um corretivo racional dos impulsos emocionais das massas (Sell, 2010, p. 141), Schumpeter considerava os cidadãos atomizados, orientados pelas suas necessidades individuais. Nesse sentido, a escolha dos cidadãos ocorre a partir das variadas opções políticas disponíveis no mercado político ou no Parlamento, que traduziriam os rumos das políticas públicas desejáveis. Desse modo, Weber e Schumpeter limitaram-se a pensar a Democracia a partir de mercados competitivos e plurais, desconsiderando, assim, contextos de concorrência restrita, de assimetria na qual alguns grupos detêm o monopólio dos recursos econômicos, políticos e culturais, que afetam tanto a formação e recrutamento das lideranças políticas e a constituição da burocracia profissionalizada como as decisões políticas.

A perspectiva formalista, minimalista e procedimental de democracia de Schumpeter influenciou e têm relevância na literatura especializada. A característica eleitoral e representativa ainda é uma das características fundamentais daqueles que objetivaram classificar sistemas ou regimes democráticos. Robert Dahl (1997), por exemplo, e uma gama de estudos posteriores tomam como condições para um modelo aproximado de Poliarquia uma série de características que têm relação com a democracia competitiva, tais como: A) O direito a formular preferências (liberdade de formar e aderir a organizações; liberdade de expressão, Direito ao voto; Direito de líderes políticos disputarem apoios; fontes alternativas de informação); B) Oportunidade de exprimir preferências (Além das condições anteriores é preciso elegibilidade para os cargos públicos e eleições livres e idôneas); C) Preferências consideradas no governo (Todas as condições anteriores mais 
Sociologias, Porto Alegre, ano 17, oo 38, jan/abr 2015, p. 156-191

a existência de instituições que garantam que as políticas governamentais dependem de eleições e de outras manifestações de preferência).

Esse argumento é endossado, dentre outros, por Adam Przeworski (1985), o qual afirma que o elemento procedimental da democracia é a chave explicativa dos processos políticos, dado que o indivíduo no mercado político escolhe, conforme suas preferências, o programa que mais o agrada, e o Partido Político ou o candidato eleito busca otimizar suas ações com o objetivo de manter-se no poder ou ser reeleito num próximo pleito eleitoral. Assim, o procedimento democrático consiste num meio de regulação de conflitos, pois a luta política fica restrita à esfera eleitoral.

Portanto, dentre outros aspectos, a questão da formação de preferências - individuais - e da agregação ou não dessas preferências adquiriu um papel central para compreender o método democrático procedimental, em especial para a corrente do individualismo metodológico. A partir da assertiva de Jonh Elster (1999), de que os indivíduos são propositivos, ou seja, suas ações são dotadas de intencionalidade, uma série trabalhos empíricos, seja através da teoria dos jogos, da escolha racional, dentro de seus limites, vem debatendo a validade teórica desses pressupostos. Conforme Maria (2010), desde a crítica schumpeteriana ao conceito de bem comum, da construção da vontade coletiva originada na teoria política clássica, os trabalhos nessa perspectiva tendem a analisar mais a questão do accountability vertical e do desenho institucional nas democracias contemporâneas do que a questão da formação e agregação das preferências individuais.

Dado esse panorama, aprofundou-se o debate sobre a crise e os limites da democracia representativa, minimalista, baseada em procedimentos, por ela supostamente ter sido incapaz de solucionar o problema do acesso dos diversos atores sociais ao debate público e, mais ainda, não ter sido capaz de dar alternativas ao problema da exclusão e da desigualdade social. Nesse entendimento, a democracia participativa constituiu- 
-se como um modelo de democracia alternativo ao representativo, ao enfatizar a questão da participação como método para enfrentar a exclusão social e promover a cidadania (Cunningham, 2009).

A partir do sentido original do termo democracia - governo do povo - e resgatando as noções de bem comum, vontade coletiva, soberania popular e igualdade, de autores clássicos como Rousseau, Toqueville, Stuart Mills, os defensores da democracia participativa buscaram, a partir da década de 1960 e 1970, desmistificar a noção de que o cidadão é incapaz, ou desinteressado nos processos políticos. Nesse sentido, Pateman (1992) ponderou que, mesmo que o pressuposto da apatia, da dificuldade em agregar preferências coletivas seja válido, pode ser transformado pelo aprendizado adquirido pelos indivíduos quando inseridos nos processos decisórios, uma vez que, como resultado da sua participação na tomada de decisões, o individuo é ensinado a distinguir entre seus próprios impulsos e desejar, aprendendo a ser tanto um cidadão público, quanto privado (Pateman, 1992, p. 39).

Portanto, o aspecto pedagógico - como aquele formulado por Rousseau - da participação política é, nessa perspectiva, o elemento chave para a tomada de decisões coletivas. Anteriormente, porém, Macpherson (1978) - inspirado pelas colocações de John Stuart Mills sobre a expansão das liberdades políticas - já havia atentado para o fato de que a participação muda a motivação individual e coletiva, uma vez que a comunidade deixa de apenas consumir e aceitar as políticas públicas e assume a promoção de suas próprias decisões políticas. Os autores dessa perspectiva sugerem a criação de instituições com novos canais de participação, os quais possam construir um cidadão participativo e interessado nos processos políticos.

As críticas ao conteúdo da democracia participativa - de forma similar àquelas feitas ao individualismo metodológico, que atentam para a omissão do contexto histórico-cultural na construção de preferências como um indicador explicativo das ações políticas -, grosso modo, refe- 
rem-se ao fato de se considerar a participação como um fim em si mesmo, deixando de lado outras variáveis e outros resultados mais significativos para a questão democrática.

Para Leonardo Avritzer e Boaventura de Souza Santos (2002), se, em meados do século XX - até final da 2ª Guerra Mundial, o debate teórico hegemônico pautava-se na desejabilidade da democracia (superando o temor e o preconceito à ascensão da grande massa desqualificada), tal debate não facilitou a ampliação da participação, uma vez que ocorreu a restrição das formas de participação e soberania ampliadas, em favor de um consenso em torno do procedimento eleitoral para a formação de governos. Entretanto, no argumento dos autores, para fazer frente a essa forma de compreender a prática da democracia - inclusive rompendo com as propostas teóricas do pós-guerra, que viam nas condições estruturais para a democracia (Barrington Moore) e na virtualidade redistributiva da democracia (Adam Przeworski) a explicação para mais ou menos democracia -, surge um grupo de teóricos, especialmente Jurgen Habermas e Joshua Cohen, cuja propensão era examinar a democracia local e a possibilidade de variação no interior dos Estados nacionais a partir da recuperação de tradições participativas solapadas no processo de construção de identidades nacionais homogêneas (Avritzer e Santos, 2002).

Nesses termos, se o primeiro grupo de autores não considera o papel da mobilização social e da ação coletiva na construção democrática, com a consequente supervalorização do papel dos mecanismos de representação, o segundo grupo reclama a combinação dos mecanismos de representação com os mecanismos societários de participação. Assim, a participação da sociedade civil nos processos decisórios é amparada e institucionalizada dentro dos marcos da democracia representativa (Jacobi, 1996).

Entretanto, não se trata de pensar num formato de ruptura com o modelo de representação político-eleitoral tradicional. Conforme assinala 
Bobbio (2002), o processo de democratização vivido hoje não se fundamenta na passagem da democracia representativa para a democracia direta; mas, diferentemente, na transição da democracia política para a democracia social, na extensão do poder ascendente (de baixo para cima) do campo da sociedade política para o da sociedade civil. O desenvolvimento atual da democracia não é a afirmação de um novo tipo de democracia, mas a ocupação pela democracia representativa de novos espaços, até então dominados por organizações do tipo hierárquicas ou burocráticas. Tem-se, assim e então, a passagem da democratização do Estado para a democratização da sociedade (Bobbio, 2002).

A questão levantada pelos teóricos que argumentam em torno da democratização da sociedade, como Boaventura dos Santos, é que o sentido da Democracia foi esvaziado com a hegemonia histórica do modelo procedimental. Seria preciso institucionalizar um modelo contra-hegemônico de Democracia, em que emergissem novas formas, novas gramáticas de organização da sociedade e de relação entre o Estado e a sociedade. Novos modos de relação da sociedade civil com o Estado, que redefinissem as identidades presentes nos Estados democráticos considerando suas demandas nas políticas públicas (Avritzer e Santos, 2002).

Cohen e Arato (1997) reforçam o argumento da necessidade da democratização das estruturas estatais visando à participação dos movimentos da sociedade civil no desenho das políticas públicas. Para os autores, o desenvolvimento da democracia participativa, especialmente em países de democratização recente, como o caso do Brasil, depende da relação mais próxima entre Estado e sociedade civil, ou seja, da abertura de espaços em que a sociedade possa se manifestar. Retomando Cohen e Arato (1997), esses autores enfatizam alguns efeitos diretos dos movimentos sociais no sistema político: a) ampliação dos limites da política; b) mudanças nas regras e procedimentos políticos; e c) transformação 
nas formas de participação no interior dos sistemas políticos. Portanto, os autores reconhecem a importância de organizações da sociedade civil na mediação de relações com o Estado, na defesa de interesses plurais e nas deliberações nos diferentes espaços participativos.

A partir da década de 1990, a teoria democrática deu uma guinada em torno do conceito de deliberação (Dryzek, 2000). A democracia deliberativa, como a vertente que Jürgen Habermas formulou, apresentou-se como contraponto, além aos pressupostos da democracia de cunho liberal, procedimental e minimalista, ao modelo republicano (participativo) de democracia, em especial ao seu aspecto cívico, os quais os indivíduos seriam dotados de virtudes políticas. Como argumentou Habermas (1995) em relação ao aspecto ético subjacente desse modelo:

Em situações de pluralismo cultural e social, por trás das metas politicamente relevantes, muitas vezes escondem-se interesses e orientações valorativas, que entram em conflito na perspectiva de consenso, necessitam de um equilíbrio ou de um compromisso que não é possível alcançar mediante discursos éticos, ainda que os resultados se sujeitem á condição de não transgredir os valores básicos consensuais de uma cultura (Habermas; 1995, p.44).

Portanto, o reconhecimento do pluralismo cultural e social, bem como dos conflitos de interesses sociais estimula o autor (Habermas) a redefinir a democracia, deslocando o foco da cidadania virtuosa para a dos espaços públicos e dos procedimentos comunicativos (Lüchmann, 2002, p.2-3). Assim, o modelo deliberativo apresentado por Habermas, inspirado nas questões colocadas pela Teoria Crítica, sustentava que a interação discursiva entre os cidadãos e representantes constitui o aspecto essencial para a formulação das decisões políticas e no processo de reconhecimento de direitos, liberdades e reivindicações individuais.

Neste modelo, conceitos como esfera pública e sociedade civil tornaram-se essenciais para a compreensão do processo de deliberação. No 
Sociologias, Porto Alegre, ano 17, no 38, jan/abr 2015, p. 156-191

primeiro, prevalece a autoridade do melhor argumento, através da participação igualitária e pública dos cidadãos, e, com a inserção dos atores da sociedade civil, amplia-se a agenda de debate público com novos temas, objetos de discussão pautados pela argumentação racional. Nesse sentido, a inserção dos atores da sociedade civil na esfera pública representa uma aproximação com o mundo da vida, dado que os atores da sociedade civil - advindos de instituições não econômicas, não estatais - estão mais próximos dos problemas e das demandas do cidadão comum.

Entretanto, com o crescimento do sistema (que engloba os subsistemas político e econômico), os processos mediados linguisticamente, que objetivam o consenso, assumem uma posição secundária e vão sendo colonizadas pelos meios de controle do sistema, como o dinheiro, o mercado e a burocracia. Com o avanço do Capitalismo ocorre um "desacoplamento" entre o sistema e o mundo da vida. O Estado e o subsistema econômico penetram o mundo da vida de tal modo que promovem uma progressiva racionalização que afeta o potencial comunicativo do mundo da vida. Portanto, no entendimento de Habermas (1995), nesse processo de diferenciação impulsionado pela modernização social, quando a instância política não atende às necessidades da sociedade civil, o conflito entre o sistema e o mundo da vida se intensifica.

Paralelamente às questões colocadas por Habermas, outras vertentes acerca do problema e limites da deliberação pública desenvolveram-se, como o liberalismo igualitário de Jonh Rawls. O problema fundamental levantado por Rawls (2002) refere-se, sinteticamente, aos padrões desiguais de distribuição de recursos - seja econômico, social ou político - que impedem o desenvolvimento das liberdades individuais. Assim, os direitos fundamentais não são suficientes para que cada cidadão defenda-se na esfera pública, já que estão em condições - especialmente econômicas - desiguais de deliberação e produção de decisões públicas. Dada 
Sociologias, Porto Alegre, ano 17, oo 38, jan/abr 2015, p. 156-191

esta constatação, Rawls (2002) apresentou uma concepção restrita do processo deliberativo, previsto em eventos e ambientes específicos como, por exemplo, a Suprema Corte Americana.

Portanto, enquanto Habermas preocupava-se com a legitimidade dos critérios dos procedimentos discursivos, Rawls (2002) argumentou em torno da justiça, ou seja, como a democracia poderia produzir condições igualitárias de oportunidades políticas ou de justiça social. Dessas duas visões, desdobraram-se dois ramos de analistas deliberativos: por um lado aqueles inspirados na recuperação da dimensão moral da democracia, da justiça igualitária (Mouffe, 2005), como Joshua Cohen, Amy Gutmann e Dennis Thompson, dentre outros; e, por outro, aqueles que compreendem a deliberação no seu sentido amplo, a exemplo de Habermas, como James Bohman, John Dryzek e Seyla Benhabib, etc.

Como contraponto ao liberalismo igualitário, em especial seu pressuposto igualitário, que pode ser compreendido como uma posição normativa segundo a qual uma sociedade democrática justa é aquela comprometida com a garantia de direitos básicos iguais e uma parcela equitativa dos recursos sociais escassos - renda, riqueza e oportunidades educacionais e ocupacionais- a todos seus cidadãos (Vita, 2002, p.1), surgiu, nas últimas décadas, a vertente teórica que ficou conhecida como a objeção multiculturalista ao liberalismo. Trata-se, sinteticamente, daquelas premissas que postulam que o liberalismo igualitário negligenciou o reconhecimento das identidades culturais dos grupos minoritários.

Esses programas notabilizaram-se pelo argumento de que, para se pensar em justiça social, é necessário prestar atenção a dois tipos de reivindicações sociais - a redistribuição e o reconhecimento (Fraser, 2000; 2001) - para que haja a inclusão política dos grupos sub-representados nos processos democráticos, especialmente quando estes grupos são minoria ou estão sujeitos a desigualdades estruturais (Young, 2000; 2006) ou culturais. 
Segundo Fraser (2000), a luta por reconhecimento tornou-se a forma paradigmática do conflito político no fim do século XX. No entanto, é preciso resgatar a questão econômica, de classe, no debate contemporâneo, para entender a questão da exclusão, pois disputas por reconhecimento acontecem em um mundo de desigualdade material exacerbada (Fraser, 2001, p.245). Cultura e economia política estão sempre entrecruzadas e, assim, toda luta contra a injustiça implica demandas por redistribuição e reconhecimento.

Em busca de uma explicação da razão da mobilização de diversos movimentos sociais que contestam injustiças, a autora distingue duas compreensões de injustiça. A primeira é a socioeconômica, enraizada na estrutura político-econômica da sociedade (exploração; marginalização econômica; privação). A segunda é cultural ou simbólica e está arraigada em padrões sociais de representação, interpretação e comunicação (dominação cultural, não-reconhecimento e desrespeito). Mas esta distinção é somente analítica, porque, na prática, ambas estão interligadas.

Os exemplos oferecidos são dois casos extremos e tipos ideais. O primeiro é o da classe trabalhadora, na concepção marxista, que sofre uma injustiça que é essencialmente um caso de distribuição. Apesar de seus integrantes sofrerem injustiças culturais sérias, estas são diretamente derivadas da economia política. O remédio para este caso é a redistribuição, e não o reconhecimento. O segundo exemplo, no outro extremo, é um tipo ideal de coletividade totalmente ajustada ao modelo de reconhecimento da justiça enraizado na cultura. Assim, qualquer injustiça estrutural que seus integrantes sofram será rastreável à estrutura cultural-valorativa.

Porém, existem coletividades que são ambivalentes, sofrem injustiças ligadas à economia política e à cultura, simultaneamente. Essas, conforme estes modelos teóricos, precisam de ambos os remédios, reconhecimento e redistribuição. Tanto gênero quanto raça são coletividades ambivalentes. Nesse sentido, em certos momentos, é necessária uma combinação 
de ações de reconhecimento e de redistribuição, pois as injustiças têm uma dupla dimensão, simbólica e econômica.

Portanto, no interior desse debate, existe o problema da exclusão de grupos sociais dos assuntos públicos. Demandas por reconhecimento, redistribuição e por políticas de presença estão na pauta do dia e colocam em cheque a representação entendida como ideias compartilhadas entre representantes e representados, sem qualquer referência à identidade dos representantes. Desse modo, somente a participação limitada ao momento do voto, na experiência de democracia representativa, não contempla as especificidades das atuais democracias contemporâneas.

Assiste-se, dessa forma, a um processo de pluralização dos atores de representação e de diversificação do lócus onde ela é exercida, o que tem mobilizado a teoria democrática. Dentre as questões levantadas, a da representação nos espaços participativos, assim como a da inclusão de grupos sociais específicos nos processos de representação política têm garantido seu espaço na agenda democrática.

Se, para todas as questões sobre o desgaste da democracia representativa, formalista, as soluções apresentadas referem-se a aperfeiçoar os meios de fiscalização e controle das instituições políticas (accountability horizontal e vertical), para a da inclusão de grupos considerados prejudicados e marginalizados na representação política, apresentam-se quatro propostas:

(1) Ampliação da representatividade mimética do corpo decisório, isto é, tornar os governantes mais parecidos com os governados; (2) ampliação da pluralidade de vozes e perspectivas presentes nas esferas decisórias; (3) ampliação da força política de grupos tradicionalmente marginalizados e; (4) ampliação da rotatividade nos cargos decisórios, impedindo a cristalização de uma elite política (Miguel, 2005, p. 32).

Tais propostas amparam-se em discussões teóricas, muitas vezes normativas, cujo fundamento, grosso modo, remete a analogia do espe- 
Iho, ou seja, que o corpo político reflita os grupos sociais os quais representa. Nesse sentido, Hanna Pitkin $(1967 ; 2006)$, em sua reflexão sobre as diferentes dimensões da representação política moderna, apresenta, de modo crítico, a representação descritiva. Segundo a autora, neste tipo de representação o corpo de representantes deve formar um microcosmo da sociedade representada, reproduzindo, nas proporções adequadas, suas características principais.

Portanto, o representante não atua pelos outros, ele os representa por virtude de uma correspondência ou conexão entre eles, uma semeIhança ou reflexo (Pitkin, 1967). Neste tipo de representação, os representantes compartilham as características sociais ou demográficas dos representados, não as demandas coletivas. Anne Phillips (1995) acrescenta que, em relação à representação dos grupos marginalizados, nos processos representativos, esses precisam estar representados fisicamente nas instâncias políticas para que suas demandas identitárias sejam levadas em conta nas arenas decisórias. Logo, o simples fato da presença é uma variável importante no reconhecimento político desses grupos.

Andrew Arato (2002) chama a atenção para os problemas que a representação descritiva acarreta. Primeiro, a questão da preparação, pois se os eleitos devem representar os grupos sociais de forma estrita, terá que haver uma preparação como na tradição dos sovietes supremos, que dificilmente podem ser vistos como paradigmas ideais da representação democrática (p. 91). Outro limite refere-se à liberdade individual, que representa o próprio conceito do sufrágio - uma pessoa, um voto -, uma vez que

se os grupos devem votar em seus próprios representantes (e quem determina quais grupos podem votar?) o resultado leva a uma representação pictórica somente se os eleitores forem obrigados a votar em uma representante de seu próprio grupo -uma regra incompatível com a liberdade de se candidatar ou de votar de forma livre (Arato, 2002, p. 91). 
Desse modo, segundo Arato, o meio possível, mas não suficiente, para gerar uma representação descritiva é o modelo proporcional de representação eleitoral.

Young (2006), por sua vez, argumenta que a relação entre representantes e representados supõe a diferença, não a questão identitária. Assim, a representação política não deve ser pensada como uma relação de identidade ou substituição, mas como um processo que envolve uma relação mediada dos eleitores entre si e com um representante (Young, 2006, p. 147). Nesse sentido, argumenta:

Pensar a representação em termos de différance em vez de identidade significa levar em conta a sua temporalidade. A representação é um processo que ocorre ao longo do tempo e tem momentos ou aspectos distintos, relacionados entre si, mas diferentes uns dos outros. A representação consiste num relacionamento mediado entre os membros de um eleitorado, entre este e o representante e entre os representantes num organismo de tomada de decisões. $\mathrm{Na}$ qualidade de um relacionamento prolongado entre os eleitores e seus agentes, a representação oscila entre momentos de autorização e de prestação de contas: é um ciclo de antecipação e retomada entre os eleitores e o representante, no qual seus discursos e ações devem carregar vestígios de um momento a outro. (Young, 2006, p. 148)

Assim sendo, segundo Young (2006, p.155), a questão da representação está conectada com os processos de autorização e prestação de contas enquanto relações construídas no decorrer do tempo, mas também com outras questões, como os interesses, as opiniões e perspectivas diferenciadas do eleitorado e dos representantes da sociedade civil. Portanto, defende que os grupos sociais não devem ser representados por uma lógica identitária, mas sim a partir de uma lógica relacional em que os indivíduos seriam compreendidos como posicionados nas estruturas dos grupos sociais, sem que estas determinem suas identidades (Young, 2006, p. 155). 
Sociologias, Porto Alegre, ano 17, no 38, jan/abr 2015, p. 156-191

Assim como os autores acima colocam em cheque a democracia representativa, alguns outros têm reiterado a legitimidade das formas não- eleitorais de participação política e a efetiva representação no interior dos espaços públicos. Nádia Urbanati (2006), com tal intuito, baseada na teoria política de Condorcet, pondera que as eleições não dão conta da totalidade de relações entre o Estado e a Sociedade Civil, e John Dryzek (2000) sustenta que, atualmente, uma série de novas formas de discursos, distintos do eleitoral, foram incorporados às instituições políticas modernas. Portanto, existem outras esferas e demandas representativas, que atuam simultaneamente à representação eleitoral, mas baseadas em outras dinâmicas. Em relação a estas esferas que produzem decisões políticas, as questões colocadas para a teoria democrática, nesse momento, referem-se ao representante.

Ao contrário do representante eleito, o dessas esferas pode ser considerado um ator que advoga em termos de causas coletivas, um representante que atua pelas causas identitárias de seu grupo, ou um indivíduo que defende ideais e valores desvinculados do grupo da sociedade civil que o colocou nessas arenas. Desse modo, essas questóes referem-se à representação no interior dos espaços deliberativos, como analisaremos abaixo, dentre outras questões das teorias democráticas, para o caso brasileiro.

As questões analisadas a seguir se referem ao alcance dessas teorias democráticas em relação ao caso brasileiro. Ou seja, analisa-se até que ponto essas abordagens permitem problematizar e compreender a relação Estado e sociedade a partir das inovações participativas que introduziram novos atores e temas na agenda estatal 


\section{Entre a normatividade e a prática: A Democracia representativa e as inovações institucionais democráticas no Brasil.}

O debate entre democracia representativa, participativa e deliberativa se estende assim, ora contrário à participação, ora favorável a ela. E esse debate só muda de perspectiva na segunda metade do século XX, passando a haver, então, uma interlocução promissora entre as duas formas, ou seja, baseada justamente na ideia de que a democracia representativa torna-se consubstanciada, ou só se torna legítima, se combinada à democracia participativa.

Conforme destacam Moura, Lacerda e Almeida (2011), os teóricos da democracia participativa defendem a tese de que há uma inter-relação entre os indivíduos e as instituições, uma vez que a participação tem função educativa, e os indivíduos são afetados psicologicamente ao participarem do processo de tomada de decisão, o que só é possível a partir do momento em que eles passam a tomar parte nos assuntos públicos e considerar o interesse público.

Ha um consenso em que o sistema representativo não dá conta de, por si só, aprofundar a democracia e, por isso, propugna-se pela necessidade de aumentar a presença da sociedade civil em formas alternativas de representação, principalmente através da criação de espaços em que ela possa se manifestar (Santos, 2002; Avritzer, 1994; Costa, 1995; Gohn, 2000). Entretanto, Côrtes (2005) enfatiza que a maior presença de membros da sociedade civil em formas alternativas de representação não é garantia de que o sistema se torne mais justo, ou de que eles tenham mais qualidades que os representantes políticos tradicionais. É preciso, assim, problematizar a noção de que existiria uma positividade inerente à participação da sociedade civil (Côrtes, 2005). 
Sociologias, Porto Alegre, ano 17, no 38, jan/abr 2015, p. 156-191

Desse modo, torna-se necessário refletir sobre os limites das abordagens que tratam a democracia participativa como um novo arranjo que faz avançar a democracia, mas que não refletem sobre como práticas instrumentais (como o clientelismo dos políticos, o personalismo das lideranças carismáticas e o controle das informações pelas lideranças comunitárias) podem se reproduzir nesses espaços participativos da mesma maneira que na política tradicional.

Entende-se, portanto, que é necessário pensar num modelo de democracia que conviva tanto com os ideais representativos, quanto com os ideais participativos, e que contribua para o aprofundamento de ambos. Por isso, é importante compreender como vêm acontecendo iniciativas de grupos, movimentos e diversas organizações na luta contra as formas de exclusão e a favor da pluralização cultural e do reconhecimento de novas identidades.

No Brasil, o debate sobre participação, especificamente no período de transição - entre fins da década de setenta e final dos anos oitenta do século XX -, apresentava-se fortemente marcado pelo contexto político-ideológico da época. Frente à experiência da ditadura militar, o Estado e, mais do que isto, o campo político institucional passa a ser apresentado como o espaço do autoritarismo, sendo os seus agentes identificados como responsáveis pela opressão e repressão aos interesses sociais excluídos do bloco no poder. Por outro lado, a sociedade civil torna-se o campo da resistência ao poder autoritário, com uma homogeneização discursiva dos seus agentes, então percebidos como democráticos, autônomos e portadores da dinâmica da transformação social e política do país (Silva, 2003). O marco da transição é a Constituição Federal promulgada em 1988: A Constituição de 88 definiu um novo arranjo federativo, com significativa transferência de capacidade decisória, funções e recursos do governo nacional para os estados e, especialmente, para os municípios (Almeida, 1995, p.92). 
Sociologias, Porto Alegre, ano 17, oo 38, jan/abr 2015, p. 156-191

Segundo Côrtes (2005), são muitos os autores que consideram de forma otimista os novos espaços de participação social, como os conselhos e orçamentos participativos (Santos, 2000; Avritzer, 2000; Costa, 1997; Boschi, 1999; Dagnino, 2002; Evans, 2003; Fung e Wright, 2001; Gohn 2001), e, de acordo com eles, esses espaços teriam uma importância central para a criação da democracia participativa e para a melhoria da gestão pública. Esses autores veem com bons olhos os espaços participativos na formulação e implementação de políticas públicas e na criação de outro tipo de democracia em contraste à democracia representativa.

Os conselhos gestores são hoje tão importantes quanto os espaços legislativos na mediação entre sociedade e Estado e para a representação e participação do interesse coletivo. Esses conselhos têm sido criados desde o nível municipal até o nível federal e passam a ser, em muitos casos, condição para que o município receba determinadas verbas para as chamadas áreas sociais, principalmente nas áreas de saúde, assistência social, educação, direitos da criança e do adolescente etc. Conforme destacado por Almeida e Tatagiba (2012), mesmo que os conselhos não tenham poder efetivo para decidir sobre a política pública, eles têm poder de veto sobre as decisões do governo, podendo paralisar obras, vetar convênios, suspender o repasse de recursos entre outras coisas. As autoras ainda destacam a importância desses espaços enquanto formadores de consciência crítica e aprendizado, tanto para os membros da sociedade quanto para os membros do Estado, realçando esses espaços como canais potenciais de transformação da cultura política brasileira, destarte as dificuldades enfrentadas (baixa participação; falta de capacitação; rotatividade dos membros; falta de divulgação, etc.).

Os Orçamentos Participativos vistos como espaços de participação direta da sociedade na defesa de interesses das comunidades também se destacam como fóruns deliberativos (Côrtes, 2005) e conforme vários es- 
tudos (Abers, 2000; Baiocchi, 2005; Avritzer e Navarro, 2003) esses espaços contribuem para a introdução de uma cultura política de participação. Entretanto, a análise desses espaços não deve desconsiderar o contexto político-ideológico em que eles são implementados. Conforme destacam Silva e Baiocchi (2014), a presença de gestores públicos com sensibilidade e movidos por ideários de transformação social combinado à presença de um associativismo consolidado influencia positivamente a alteração de uma cultura política tradicional de dependência do Estado em direção a uma ação que pode sustentar um novo projeto de sociedade.

Um dos principais argumentos utilizados por teóricos e políticos defensores da descentralização e da introdução de mecanismos participativos na administração pública municipal assenta-se na hipótese de que eles garantiriam mais eficiência, eficácia e efetividade nas políticas públicas. Além disso, possibilitariam romper com o clientelismo e o patrimonialismo. De acordo com Silva e Marques (2004, p.11),

a descentralização, juntamente articulada à participação social, também é um elemento marcante dos discursos e propostas políticas democratizantes dos anos 80 e 90, no Brasil. O reforço e o maior protagonismo das esferas subnacionais (estados e municípios), como contraponto à significativa centralização que marcou a formulação e implantação das políticas públicas durante os governos militares, se apresentava como uma condição de superação de diversos impasses e problemas identificados na atuação do Estado brasileiro (ineficiência, excessiva burocratização, distanciamento em relação às necessidades sociais, corrupção, autoritarismo etc.).

Alguns autores, contudo, têm uma posição menos otimista com relação a esses espaços, quando sustentam que o desempenho da gestão local estaria, em princípio, obstruído por inúmeras razões, as quais remetem de maneira geral à incapacidade político-institucional dos municípios - fragilidade financeira; reduzida capacidade organizacional; tradição de 
Sociologias, Porto Alegre, ano 17, no 38, jan/abr 2015, p. 156-191

práticas clientelistas ou ausência de um capital social aprimorado capaz de atuar como partícipe de uma gestão social (Pinto, 2004; Côrtes, 2005).

Essa proposta de participação "semi-direta" na gestão pública, ou seja, a "institucionalização da participação"1 , tem se manifestado em algumas experiências dos conselhos municipais instituídos por meio de legislação nacional, a qual condiciona a transferência de recursos para os municípios à criação desses conselhos. Mas, será mesmo que a incorporação dessa "institucionalidade democrática e participativa" nas ações dos atores sociais contribui firmemente para a possibilidade de aperfeiçoamento das práticas e de modelos administrativos capazes de possibilitar um melhor "desempenho" das instituições políticas?

Como mostra Arretche (1999, p.25),

\begin{abstract}
no caso brasileiro - um Estado federativo, em um País caracterizado por expressivas desigualdades estruturais de natureza econômica, social, política e de capacidade administrativa de seus governos -, atributos estruturais das unidades locais do governo tais como a capacidade fiscal e administrativa e a cultura cívica local, têm um peso determinante para a descentralização. Mas tais fatores não são determinantes em si. Seu peso e importância variam de acordo com requisitos institucionais postos pelas políticas a serem assumidas pelos governos locais [...].
\end{abstract}

Arretche (1996) e Côrtes (2005) problematizam a visão de que estes espaços teriam uma relação direta com o aprofundamento da democracia e, portanto, com os resultados sociais esperados, tentando mostrar que a concretização dos ideais democráticos depende muito mais da natureza das instituições que processam as decisões do que do nível de governo encarregado da gestão das políticas.

${ }^{1}$ Entende-se por institucionalização da participação os mecanismos formalmente criados pelo governo municipal que inserem a participação da população na gestão de políticas públicas. 
Fóruns têm papéis diferenciados nos contextos institucionais e políticos em que se inserem e potencialidades muito diversas em termos de impactos sobre a formulação ou implementação de políticas públicas, tendo em vista seus desenhos institucionais e os desenhos institucionais do setor ou programa ou da política em que se inserem (Côrtes, 2005, p.13).

Sabe-se que a participação da sociedade civil na definição, formulação e na gestão das políticas públicas é elemento fundamental para o avanço democrático; entretanto, isto não significa garantia de que ocorra uma efetiva ampliação dos direitos sociais aos excluídos (Raichelis, 2000).

Mas, mesmo que exista esse risco da qualidade da democracia e da participação em alguns espaços institucionalizados, como é o caso dos conselhos municipais, Abramovay (2001) chama a atenção para a existência de conselhos gestores como uma das mais inovadoras experiências em formas de gestão de recursos públicos. Por mais que os conselhos ainda tendam a reproduzir um ambiente contrário à ampla discussão de assuntos públicos, a sua simples existência coloca pessoas que até então não tinham acesso à discussão dos assuntos públicos inseridas no debate desses temas, antes ausentes de sua vida.

Se os primeiros estudos e análises destacavam as potencialidades desses espaços participativos criados a partir da Constituição de 1988 como os Conselhos Gestores, os Orçamentos Participativos, os Fóruns -, baseados nas colocações de Jürgen Habermas, após a institucionalização desses espaços, novas questões emergiram, a exemplo do debate sobre representação, como sintetiza Lígia Lüchmann:

As experiências participativas n Brasil, a exemplo dos conselhos gestores dos orçamentos participativos, apontam para um movimento de renovação e de reacomodação destes instrumentos de ação política no interior das práticas institucionais da sociedade brasileira, indicando que, muito menos que oposição, estes instrumentos estabelecem combinações e articulações que desenham um processo de 
concomitante inovação e reprodução das práticas e orientações políticas-institucionais. Apontam, sobretudo, para o fato de que a participação não substitui, mas reconfigura a representação, constituindo-se a participação em chave da boa representação (Lüchmann, 2007, p. 167).

Nessa discussão sobre a representatividade dos espaços participativos como instituições de controle social em relação ao governo representativo, emergiram questões inspiradas nas colocações de Pitkin, Young, Urbanati e Philips, sobre a representação social e política e sua legitimidade dentro de espaços de participação (Moura e Monteiro, 2010). Embora seja um debate ainda inconcluso, refere-se à composição social e política desses espaços, se os indivíduos representam grupos, ideias e valores, causas coletivas ou buscam retificar as ações governamentais e como o fazem.

Esse debate relaciona-se ao desenho institucional de cada um dos espaços participativos surgidos após a Constituição de 1988. Conforme Avritzer (2008), existe atualmente, no Brasil, uma variedade de instituições participativas com desenhos institucionais distintos que exercem impactos diferenciados na democratização do governo, e na efetividade deliberativa. Os Orçamentos Participativos, por exemplo, criados no Brasil a partir da experiência de Porto Alegre pelo Partido dos Trabalhadores, têm um desenho participativo de baixo para cima, de livre entrada, em que a representação se dá por todos participantes através da eleição de delegados e conselheiros. Já os Conselhos de Política constituem um desenho participativo de partilha do poder, em que atores da sociedade civil e do governo participam simultaneamente, sendo determinados por lei. Os Planos Diretores Municipais, por sua vez, representam um desenho participativo de ratificação em que os atores da sociedade civil são chamados para ratificar as decisões públicas, não formular. Esses modelos exercem impactos diferenciados, como descreve Leonardo Avritzer: 
Não existem dúvidas de que os desenhos de baixo para cima como o OP são os mais fortemente democratizantes e distributivos. Os casos dos desenhos de partilhas são os mais fortemente democratizantes nos caso de oposição à participação por parte da sociedade política. Os casos de ratificação são os casos mais efetivos quando há necessidade da sanção por parte do judiciário e do ministério público para a manutenção das formas de participação previstas em lei (Avritzer, 2008, p. 60).

Portanto, os desenhos institucionais participativos geram efeitos diversificados na democratização brasileira. O panorama descritivo apresentado até aqui demonstra que as práticas democráticas brasileiras expressam muitas das questões levantadas pelas teorias democráticas. Já não se trata de apenas saber quanto mais democrático é um governo, ou quanto mais representativo eleitoralmente, mas de como se ampliam os espaços de representação não-eleitoral na sociedade brasileira.

De todo modo, a explicação a partir dos desenhos institucionais de cada espaço participativo parece insuficiente quando se analisam os objetivos estatais na promoção da deliberação. Não explica, por exemplo, como essa relação Estado-sociedade coloniza o livre entendimento baseado no mundo da vida, afetando a formulação de políticas públicas que fortalecem a cidadania (Habermas, 1995). Assim como não problematiza o fato de o Estado e as instituições centralizadoras incorporarem as demandas participativas pela sua necessidade de legitimação. É preciso entender, também, que existem diferentes maneiras de apropriação desses espaços pelos atores sociais, e que essas diferenças são mediadas pelas assimetrias sociais (Miguel, 2014). O fato é pensar em que medida o desenho institucional desses espaços participativos consegue modificar uma relação geradora de dependência a estruturas estatais, que reproduz assimetrias de poder e de acesso às informações relevantes. 


\section{Participação e deliberação: apontamentos para uma nova tipologia}

A tipologia proposta por Avritzer (2008) atribui graus de democratização às diversas experiências participativas, pondo o OP no ápice em termos de inclusão dos cidadãos, por ser um modelo "de baixo para cima". Entretanto, outros pesquisadores que analisaram o OP como experiência concreta (Abers, 2003; Fedozzi, 2007; Silva e Baiocchi, 2014) revelam os limites dessas arenas de participação para a criação de instituições democráticas que respondam às expectativas da sociedade contemporânea.

Assim, consideramos que seria um avanço analítico averiguar em que grau as inovações institucionais das últimas décadas realizam concretamente os ideais democráticos de participação e deliberação. Nesta seção, examinamos as experiências brasileiras recentes a partir desse prisma, procurando construir uma escala teórica de participação e deliberação.

Como se sabe, os dois modelos de democracia advindos desses ideais são críticos das limitações da democracia liberal e, com frequência, aparecem juntos nos questionamentos sobre a maneira como a democracia é praticada atualmente. É comum se dizer, por exemplo, que a participação educa e informa o cidadão, ao mesmo tempo em que amplia seu senso de eficácia política. Entretanto, é lógica e empiricamente possível conceber pessoas que são extremamente militantes, mas cuja atuação se dá sem agregação de informação nova ao seu repertório político e sem mudança de opinião. A rigor, portanto, os modelos são distintos entre si (Held, 2006) e não necessariamente compatíveis um com o outro (Mutz, 2006).

No quadro 1, comparamos as características principais dos modelos participativo e deliberativo. Tomamos por base a análise desenvolvida nos trabalhos de Held (2006), Barber (2003), Smith (2009), Fishkin e Ackerman (2004), e Fishkin e Luskin (2005). Na última linha, em itálico, estão algumas experiências concretas recomendadas pelos autores filiados aos dois modelos. 
Sociologias, Porto Alegre, ano 17, no 38, jan/abr 2015, p. 156-191

Quadro 1. Comparando os modelos críticos à democracia liberal

\begin{tabular}{|l|l|}
\hline \multicolumn{1}{|c|}{ Democracia participativa } & \multicolumn{1}{|c|}{ Democracia deliberativa } \\
\hline $\begin{array}{l}\text { Participação direta dos cidadãos na regulação de } \\
\text { sua comunidade local e local de trabalho }\end{array}$ & $\begin{array}{l}\text { Fóruns públicos abertos a argumentos contrários e a } \\
\text { novos dados e informações }\end{array}$ \\
\hline $\begin{array}{l}\text { Sistema político aberto ao autogoverno dos cida- } \\
\text { dãos, com experimentos sem a mediação da repre- } \\
\text { sentação }\end{array}$ & $\begin{array}{l}\text { Grupos moldados para a proposição de políticas } \\
\text { públicas, com abertura para mudança de opinião }\end{array}$ \\
\hline $\begin{array}{l}\text { Partidos políticos com direções prestando contas } \\
\text { diretamente aos seus filiados }\end{array}$ & $\begin{array}{l}\text { Experiências com cidadãos selecionados por amos- } \\
\text { tragem representativa da população }\end{array}$ \\
\hline $\begin{array}{l}\text { Assembleias de bairro (incluindo o orçamento par- } \\
\text { ticipativo), experimentos democráticos no local de } \\
\text { trabalho, iniciativa popular de lei atada a referendos } \\
\text { de múltipla escolha }\end{array}$ & $\begin{array}{l}\text { Júris de cidadãos, pesquisa deliberativa, assembleias } \\
\text { de cidadãos, dia deliberativo, fóruns de discussão } \\
\text { via Internet (e-democracy) }\end{array}$ \\
\hline
\end{tabular}

Como podemos perceber a partir da leitura da tabela, as ênfases dos dois modelos são diferentes. Eles visam remediar dois déficits percebíveis nas democracias liberais. Do lado participativo, a carência de participação e engajamento político; do lado deliberativo, a decisão mal informada ou irrefletida característica das eleições. Embora alguns efeitos positivos possam ser os mesmos², os modelos têm valores diferenciados a se perseguir.

O esforço, doravante, dá-se no sentido de entender as experiências recentes de inovação participativa no Brasil a partir da exposição do quadro 1. Não cabe no espaço deste artigo uma plena avaliação da questão, mas algumas expectativas teóricas são cabíveis a partir do que sabemos das inovações institucionais.

Assim, o orçamento participativo se enquadraria numa categoria que combina níveis de participação significativamente mais elevados do que seus correspondentes patamares de deliberação. Não parece figurar como

\footnotetext{
${ }^{2}$ Ver, contra, Mutz (2006). Em sofisticada pesquisa empírica, a autora conclui que não é possível maximizar ao mesmo tempo os dois valores. Pessoas expostas a pontos de vista diferentes tendem a participar menos do que os indivíduos cujo convívio exibe pessoas com ponto de vista similar. O desenvolvimento de pessoas com pensamento refletido, que consideram diversas visões, reduz o fervor militante.
} 
Sociologias, Porto Alegre, ano 17, oo 38, jan/abr 2015, p. 156-191

característica integrante do OP a abertura à mudança de opinião e ao acúmulo de informações para decisões mais refletidas nas assembleias locais.

Segundo Abers (2003), esses mecanismos de participação não se constituem em arenas de influência sobre as decisões estatais, a não ser quando os governos aceitam compartilhar a autoridade e as decisões, motivados por algum interesse. Para a autora, o OP de Porto Alegre tem uma especificidade, porque contou com o apoio partidário, além de se construir a partir da ideia de sinergia entre Estado e sociedade, o que não aconteceu com outros OPs. Esses outros não se caracterizaram como fóruns participativos, porque não conseguiram dispor de autoridade, ou seja, não influenciavam a agenda das políticas públicas definidas pelos gestores. Segundo ela, “o OP não resulta em fóruns caracterizados por autoridade quando o governo não tem comprometimento político real em transferir poder decisório para o OP" (Abers, 2003; p. 280).

Fedozzi (2007) argumenta na mesma linha que Abers, observando que o poder de decisão dos participantes no OP diminuiu nos últimos anos, de acordo com a pesquisa coordenada por ele. Segundo os dados, a soma das respostas "às vezes decide" e "nunca decide", que era de 24,4\% em 1995 subiu para 36,03\% em 2005 (Fedozzi, 2007; p. 37). Para o autor, esse fator é importante se somado a outras questões para perceber que o OP prescinde de um papel ativo e de compromisso do gestor no processo de compartilhamento de poder.

Outra questão analisada por Fedozzi (2007) em relação aos dados coletados sobre o OP em três momentos distintos, 2000, 2002 e 2005, é a da representação e da cultura de participação. Ao investigar a participação no OP de delegados e conselheiros, demonstra que aqueles que participam por mais tempo do OP constroem vínculos mais sólidos com o processo, embora isso também possa indicar a estagnação da renovação de lideranças, como descreve abaixo: 
O crescimento do exercício de representação pelas mesmas pessoas pode indicar tanto o vínculo cívico proporcionado pela democracia participativa, como também a estagnação da renovação de lideranças comunitárias com certa "apropriação" das funções de representação [...] (Fedozzi, 2007, p. 26).

Portanto, os dados empíricos problematizam a ideia do OP como um tipo ideal de democracia participativa que combinaria aspectos da democracia deliberativa. O inverso poderia ser dito, nos mesmos termos teóricos, dos conselhos gestores. Tratam-se de experiências com elevado potencial deliberativo, na medida em que expõem segmentos representativos da sociedade a diferentes pontos de vista dentro de um mesmo minipúblico decisório.

No entanto, muitos representantes se constituem como detentores de saberes, formando uma espécie de elite política que tem dificuldades em dialogar com os setores tradicionalmente excluídos e, mais ainda, transformam-se em "personalidades" detentoras desse poder. Assim, sob essa ótica, não se preocupam em ter um respaldo da base, pois são os conhecedores da temática. O que se verifica, na prática, é a fragilidade dos conselheiros diante da centralização do poder nas mãos de alguns poucos, especialmente daqueles especialistas (Moura e Monteiro, 2010). A indução à participação, portanto, é limitada, até pela distância que se forma entre os conselheiros e sua suposta base representativa na população.

Nosso objetivo foi, portanto, produzir elementos preliminares para futuras avaliações empíricas do rendimento democrático das diversas inovações institucionais. Não é difícil perceber que aplicações de cunho normativo também podem ser vislumbradas, pois resta claro que certos desenhos podem ser usados para determinados objetivos e não para outros, a depender dos objetivos dos reformadores e do contexto local e institucional. 


\section{Considerações finais}

A descrição dos limites e possibilidades das teorias da democracia, mesmo que sumariamente, permite delinear o alcance e as potencialidades de seus pressupostos quando contrastados às experiências democráticas concretas, como a brasileira. A prática democrática e os avanços significativos da participação política mostram que algumas concepções da democracia privilegiam o respeito pela inclusão social e, combinadas, produzem questões pertinentes relativas ao exercício democrático propriamente dito.

Não se trata de produzir novos modelos teóricos analíticos, mas de desenvolver uma perspectiva de análise que consiga incorporar as questões da inclusão e da representação social, dando ênfase à articulação social e política nas esferas participativas. Apesar da multiplicidade de enfoques entre os expoentes da teoria democrática, há consenso entre os autores ligados a essa área de que a democracia deve produzir certos resultados sociais e políticos. É possível detectar que um modelo democrático inclusivo precisa contemplar questões referentes à formação de agenda, ao acesso de diferentes grupos sociais à esfera pública, com capacidades de deliberação (Miguel, 2003), além da possibilidade de construção de uma nova relação entre Estado e sociedade.

Acreditamos essencial sublinhar a importância da centralidade dos ideários da participação social no debate sobre os sentidos da democracia brasileira, já que isso traz desdobramentos reais para o desenvolvimento de nossa sociedade. De um lado, temos a inclusão de uma série de grupos sociais no debate sobre as políticas públicas, mesmo que existam fatores limitantes, como mostramos. Por outro lado, a própria gestão pública brasileira tem que dialogar e se abrir a essas reivindicações ou, como diria Nancy Fraser, reconhecer determinados setores e propor políticas públicas. Com isto, queremos dizer que um modelo de democracia não se refere somente a um conjunto de ideários, mas deve ser baseado num modelo real de sociedade ou numa expectativa de discussão de qual sociedade queremos. 
Lorena Madruga Monteiro - Pesquisadora do Instituto de Tecnologia e Pesquisa (ITP/ SE) e professora titular I do Núcleo Interdisciplinar de Pós-Graduação do Centro Universitário Tiradentes (UNIT-AL). Possui graduação em Ciências Sociais, UFRGS, mestrado (2006) e doutorado (2011) em Ciência Política pela UFRGS. $>$ lorena.madruga@gmail.com

Joana Tereza Vaz de Moura - Professora Adjunta Departamento de Políticas Públicas UFRN. Possui graduação em Administração, UFLA, mestrado em Ciências Sociais: Desenvolvimento, Agricultura e Sociedade, UFRRJ e doutorado em Ciência Política UFRGs. $\$ joanatereza@gmail.com

Alan Daniel Freire de Lacerda - Professor Adjunto do Departamento de Políticas Públicas UFRN. Possui graduação em Ciências Sociais pela Universidade Federal do Rio Grande do Norte (1997), mestrado (1998) e doutorado em Ciência Política pelo IUPERJ (2005), e um estágio doutoral (sanduíche) na Duke University (2002). $>$ lacerda75@msn.com

\section{Referências}

1. ABERS, Rebecca Naera. Inventing local democracy: grassroots politics in Brazil. Boulder: Lynne Rienner Publishers, 2000.

2. ABERS, Rebecca Naera. Interesses e ideias em políticas participativas: reflexões a partir dos comitês de bacias hidrográficas e orçamentos participativos. Sociedade e Estado, Brasília, UNB, vol. 18, n. 01/02, 2003.

3. ABRAMOVAY, Ricardo. Conselhos além dos limites. Revista Estudos Avançados, vol 15, no 43, set/dez, 2001.

4. ALMEIDA, Maria Hermínia Tavares de. Federalismo e Política Sociais. Revista Brasileira de Ciências Sociais, n. 28, 1995.

5. ALMEIDA, Carla; TATAGIBA, Luciana. Os conselhos gestores sob o crivo da política: balanço e perspectivas. Serviço Social e Sociedade, n. 109, São Paulo, jan/mar 2012, p. 68-92.

6. AVRITZER, Leonardo. Sociedade Civil e Democratização. Belo Horizonte: Del Rey, 1994.

7. AVRITZER, Leonardo. Democratization and changes in the pattern of association in Brazil. Journal of Interamerican Studies and World Affairs, Fall, vol.42, no3, 2000, p. 59-76. 
Sociologias, Porto Alegre, ano 17, no 38, jan/abr 2015, p. 156-191

8. AVRITZER, Leonardo. Instituições participativas e desenho institucional: Algumas considerações sobre a variação da participação no Brasil democrático. Opinião Pública, Campinas, Vol. 14, n. 1, junho, 2008, p. 43-64.

9. AVRITZER, Leonardo; SANTOS, Boaventura de S. Para ampliar o cânone democrático. In: Santos, Boaventura de Sousa. Democratizar a Democracia: os caminhos da democracia participativa, 2002.

10. AVRITZER, Leonardo; NAVARRO, Zander. A inovação democrática no Brasil. São Paulo: Cortez, 2003.

11. ARATO, Andrew. Representação, soberania popular e Accountability. Lua Nova. N. 55-56, 2002, p. 85-103.

12. ARRETCHE, Marta. Mitos da descentralização: mais democracia e eficiência nas políticas públicas? Revista Brasileira de Ciências Sociais, n.31, São Paulo, jun. 1996.

13. ARRETCHE, Marta. Políticas sociais no Brasil: descentralização em um Estado federativo. Revista Brasileira de Ciências Sociais, v.04, n.40, São Paulo, jun. 1999.

14. BAIOCCHI, Gianpaolo. Militants and citizens: the politics of participation in Porto Alegre. Stanford: University Press, 2005.

15. BARBER, Benjamin. Strong democracy: participatory politics for a new age. Berkeley: University of California Press, 2003.

16. BOBBIO, Norberto. O futuro da democracia. São Paulo: Paz e Terra, 2002.

17. BOSCHI, Renato. Descentralização, clientelismo e capital social na governança urbana: comparando Belo Horizonte e Salvador. DADOS - Revista de Ciências Sociais, n. 47, 1999.

18. COHEN, Jean L. e ARATO, Andrew. Civil society and political theory. MIT Press, 1997.

19. CÔRTES, Soraya Vargas. Fóruns participativos e governança: uma sistematização das contribuições da literatura. In: LUBAMBO, Catia; COÊLHO, Denílson B.; MELO, Marcus A. (Orgs). Desenho institucional e participação política- Experiências no Brasil contemporâneo. Petrópolis: Vozes, 2005.

20. COSTA, Sergio. A democracia e a dinâmica da esfera pública. Lua Nova, n. 36, São Paulo, 1995, p. 55-65.

21. COSTA, Sergio. Contextos de construção do espaço público no Brasil. Novos Estudos CEBRAP, n. 47, março, 1997.

22. CUNNINGHAM, Frank. Teorias da Democracia. Uma introdução crítica. Porto Alegre: Arrmed, 2009.

23. DAGNINO, Evelina (org.). Sociedade civil e espaços públicos no Brasil. São Paulo: Paz e Terra/Unicamp, 2002. 
24. DAHL, Robert A. Poliarquia. São Paulo: Edusp, 1997.

25. DRYZEK, John. Deliberative Democracy and beyond: liberals, critics, contestations. Oxford University Press, Oxford, 2000.

26. ELSTER, Jon. A possibilidade da política racional. Revista Brasileira de Ciências Sociais, vol. 14, n. 39, São Paulo, 1999.

27. EVANS, Peter. Além da "Monocultura Institucional": instituições, capacidades, e o desenvolvimento deliberativo. Sociologias, Porto Alegre, v. 5, n. 9, jan/ jun 2003, p. 20-63.

28. FEDOZZI, Luciano. Observando o Orçamento Participativo de Porto Alegre. Análise histórica de dados: perfil social e associativo, avaliação e expectativas. Porto Alegre: Tomo editorial, 2007.

29. FRASER, Nancy. Social justice in the age of identity politics: redistribution, recognition and participation. In: HONNETH, Axel; FRASER, Nancy. Redistribution or Recognition? A Political-Philosophical Exchange. London: Verso. 2000.

30. FRASER, Nancy. Da distribuição ao reconhecimento? Dilemas da justiça na era pós socialista. IN: SOUZA, Jessé (org.) Democracia hoje. (novos desafios para teoria democrática contemporânea). Brasília, UNB, 2001.

31. FISHKIN, James e ACKERMAN, Bruce. Deliberation day. New Haven: Yale University Press, 2004.

32. FISHKIN, James e LUSKIN, Robert. Experimenting with a democratic ideal: deliberative polling and public opinion. Acta Politica 40, 2005, p. 284-298.

33. FUNG, Archon, e WRIGHT, Erik Olin. Deepening democracy: innovations in empowered participatory governance. Politics \& Society, Março, vol. 29, no . 1, 2001.

34. GOHN, Maria da Glória. O papel dos conselhos gestores na gestão urbana. Repensando a experiência urbana na América Latina: questões, conceitos e valores. Ed Buenos Aires: CLACSO, 2000.

35. GOHN, M. G. M. Conselhos Gestores e Participação Sociopolítica. 1a ed. São Paulo: Cortez Editora, 2001.

36. GOHN, M. G. M.. Três modelos normativos de democracia. Lua Nova, São Paulo, n. ${ }^{\circ} 36,1995$.

37. HELD, David. Models of democracy. 3. ed. Stanford: Stanford University Press, 2006.

38. JACOBI, P. Ampliação da cidadania e participação: desafios da democratização da relação poder público/sociedade civil no Brasil. 1996. Tese (Livre Docência) - Faculdade de Educação da Universidade de São Paulo, 1996.

39. LÜCHMANN, Ligia. A representação no interior das experiências de participação. Lua Nova, São Paulo, 70, p. 139-170, 2007. 
40. LÜCHMANN, Lígia. Democracia deliberativa: Sociedade civil, esfera pública e institucionalidade. Cadernos de pesquisa, n. ${ }^{\circ} 33$, novembro de 2002.

41. MACPHERSON, Crawford Brough. A Democracia Liberal: Origens e evolução. Rio de Janeiro, Zahar, 1978.

42. MARIA, João Francisco Araújo. Desenho institucional e accountability: Pressupostos normativos da teoria minimalista. Revista de Sociologia e Política, v.18, n.35, fev. 2010, p. 27-40.

43. MIGUEL, Luis Felipe. A Democracia domesticada: Bases antidemocráticas do pensamento democrático contemporâneo. Dados - Revista de Ciências Sociais, Rio de Janeiro, Vol. 45, n. ${ }^{\circ} 3,2002$, p. 483-511.

44. MIGUEL, Luis Felipe. Representação política em 3-D: elementos para uma teoria ampliada da representação política. Revista Brasileira de Ciências Sociais, v. 18, n. 51, fev. 2003, p. 123-140.

45. MIGUEL, Luis Felipe. Impasses do Accountability: Dilemas e alternativas da representação política. Revista Sociologia e política. Curitiba, 25, Nov. 2005, p.25-38.

46. MIGUEL, Luis Felipe. Democracia e representação. Territórios em disputa. UNESP, 2014.

47. MOUFFE, Chantal. Por um modelo agnóstico de democracia. Revista Sociologia e Política, Curitiba, n. ${ }^{\circ} 25$, Nov. 2005, p.11-23.

48. MOURA, Joana Tereza Vaz de; MONTEIRO, Lorena Madruga. Democratização ou assimetria da representação: notas sobre os Conselhos de Segurança Alimentar e Nutricional. Revista Política e Sociedade, vol. 09, n. 16, abril, 2010.

49. MOURA, Joana Tereza V. de; LACERDA, Alan Daniel F.; ALMEIDA, Lindijane Souza Bento. A anatomia da participação: os conselhos como arena decisória. Plural Revista de Ciências Sociais, USP, v.18, n.01, 2011, p. 117-134.

50. MUTZ, Diana. Hearing the other side: deliberative versus participatory democracy. Nova lorque: Cambridge University Press, 2006.

51. PATEMAN, Carole. Participação e Teoria Democrática. São Paulo: Paz e Terra, 1992.

52. PINTO, Céli Regina Jardim. Espaços deliberativos e a questão da representação. Revista Brasileira de Ciências Sociais, v.19, n.54, São Paulo, fev. 2004.

53. PITKIN, Hanna F.. The concept of representation. Berkeley, CA, Los Angeles, CA and London: University of California Press, 1967.

54. PITKIN, Hanna F.. Representação: palavras, instituições e ideias. Lua Nova. Revista de Cultura e Política. № 67, 2006, p. 15-47. 
Sociologias, Porto Alegre, ano 17, o 38, jan/abr 2015, p. 156-191

55. PHILLIPS, Anne. The Politics of Presence. Oxford, Oxford University Press, 1995.

56. PRZEWORSKI, Adam. Capitalism and social democracy. Cambridge; Nova lorque, Cambridge University Press, 1985.

57. RAICHELIS, Rachel. Esfera pública e conselhos de assistência social: caminhos da construção democrática. São Paulo: Cortez, 2000.

58. RAWLS, Jonh. Uma teoria da justiça. São Paulo, Martins Fonte, 2002.

59. SANTOS, Boaventura de Sousa. A Crítica da Razão Indolente: Contra o Desperdício da Experiência. Porto: Afrontamento, 2000.

60. SELL, Carlos Eduardo. Max Weber: democracia parlamentar ou plebiscitária? Revista Sociologia Política. Curitiba, v. 18, n. 37, Oct. 2010, p. 137-147.

61. SILVA, Marcelo Kunrath. Tradições associativas populares e democracia: uma análise comparativa das experiências de Orçamento Participativo na Região Metropolitana de Porto Alegre. Anais do XXIV Congresso da ALAS, 2003.

62. SILVA, Marcelo Kunrath; BAIOCCHI, Gianpaolo. Limites intrínsecos do Orçamento Participativo. Le Monde Diplomatique Brasil, 24 de setembro 2014.

63. SILVA, Marcelo Kunrath; MARQUES, Paulo Eduardo M. Democratização e políticas públicas de desenvolvimento rural. In: Scheinder, Sérgio et al. Políticas públicas e participação social no Brasil rural. Porto Alegre: UFRGS, 2004.

64. SMITH, Graham. Democratic innovations: designing institutions for citizen participation. Cambridge: Cambridge University Press, 2009.

65. SCHUMPETER, Joseph. Capitalismo, socialismo e democracia. Rio de Janeiro, Ed. Fundo de Cultura, 1961.

66. YOUNG, Iris Marion. Civil society and its limits. In: YOUNG, Iris Marion. Inclusion and democracy. Oxford: Oxford University Press, 2000.

67. YOUNG, Iris Marion.. Representação política, identidade e minorias. Lua Nova, São Paulo, 67, 2006, p. 139-190.

68. VITA, Álvaro de. Liberalismo igualitário e multiculturalismo (sobe Brian Barry, Culture and equality). Lua Nova, n. ${ }^{\circ} 55-56,2002$, p. 5-27.

69. URBANATI, Nadia. O que torna a representação democrática. Lua Nova, São Paulo, 67, 2006, p. 191-228.

70. WEBER, Max. Parlamento e governo na Alemanha reordenada. $2^{a}$ ed. São Paulo: Abril Cultural, 1980. (Os Pensadores).

Recebido em: 26/03/2014

Aceite Final: 02/10/2014 